\title{
Allocation Time and Consumption Childcare of Working Mother in Palembang City
}

\author{
Marieska Lupikawaty* \\ Prodi Bachelor of Business Management, \\ State Polytechnic of Sriwijaya \\ Palembang, Indonesia \\ *marieska@polsri.ac.id
}

\author{
Rosmiyati Chodijah Saleh \\ Prodi Doctor of Economic Sciences \\ University of Sriwijaya \\ Palembang, Indonesia \\ roossaleh@gmail.com
}

\begin{abstract}
This study tries to analyze the influence of time allocation and consumption of child care early age of working mother who selected the type of child care in Palembang city. Data were collected by interviews, questionnaires and literature. Technical analysis of the data using binary logistic regression of two dependent variables where chosen daycare or non-daycare. The first result showed that the cost of childcare (RC) utility nondaycare Child care is higher than the Daycare, the second states that the allocation of a number of domestic hour (Ld) and the number of hours of child care at home ( $\mathrm{Lm})$ non-daycare utility greater than the Daycare. The number hours of other working mothers (Lx) is not a significant influence on the utility possibility of working mothers choosing child care. But simultaneously the respondent can allocate time above the average of 3.89 hours per day for utilities possibility of working mothers. The results of this study different from the other finding that working mothers have more less the allocation of time domestic and have hours of leisure on weekdays and have much time of domestic child care at home and working hours on weekends.
\end{abstract}

Keywords—child care consumption, allocation of time, working mothers

\section{INTRODUCTION}

This Education and health is an indicator of investment in human resources, so parents should pay attention to the education and health of their children. We usually hear that education is first and foremost is derived from the mother. Growing phenomenon in Indonesia that the female labor force who work are those that have higher education [1]. Similarly, a phenomenon that occurs in the province of South Sumatra. Women working on a diploma I / II / III / Colleges / Universities count 185.059 more than the men who worked as many as 176.148 [2].

Culturally may mean that men are required to fast work, so after graduating high school level they no longer attend school but chose to work. Unlike the graduated from the Diploma to Higher Education, is dominated by women who work. This is consistent with the theory Elfindri and Bactiar [3] one of the reasons women decide to go to work due to an increase of women's education from year to year. According from the initial interview by the author on some of the mothers who work, stated the reason they keep working even though they still have children at home early age due to the high increase in the home needs, especially for children, such as education and health. By working, they can help the family economy and not a few of those working mothers give reason to keep working due to self-actualization

Residents of South Sumatra province including having a young population structure is of the age group 0-4 years and 59 years age group. While the population aged five years and below in Palembang amounted to 148.721 children [4]. In addition to the above data reinforce the need for the needs of other people involved in the care of children of working mothers, when the working women were married and had children, raised the question of who care for and look after the children of working mothers? And mothers are the first and primary school for the children at home. This causes the mother to work after the expiration of maternity leave, usually three months, must return to work and leave their children at home with grandparents, other family even did the demand for child care services (daycare) which raises the cost per month for working mothers. Supposed to be the responsibility of caring, nurturing and educating children in the hands of the mother, but because mothers choose to keep working, this responsibility was transferred to the grandparents, family, and even transferred on a paid child care (daycare). This phenomenon began to flourish in Indonesia with the emergence of child care services, but these services predominantly come from the private sector and not the government. As quoted from the reportpolicy review of Education and Early Childhood Care in Indonesia [5] conducting research on family policy and early childhood care and education in Indonesia. Finding that there was no government investment in nursery education and early childhood care. Almost $100 \%$ privately held and parents who bear the brunt. So no additional costs to keep the child for working mothers. Additional costs in the household can be covered by income received by working mothers.

After returning to work, the mother returned to be prosecuted doing work at home such as cooking, doing housework, caring for her husband and children at home. Because this is the duty of a wife and mother, so it's very interesting to see how a working mother divides her time and balance with activities outside the household and in the household. This study tries to analyze the influence of time allocation and consumption of child care early age of working 
mothers who do the selecting the type of child care in the city of Palembang.

\section{LITERATURE}

Household theory of Becker [6] is assumed to combine time and goods to produce goods that are directly entering the household utility function. Production of household commodities are called $\mathrm{Z}$ by function:

$$
\mathrm{Zi}=\text { fi (xi, Ti) }
$$

Where: $\mathrm{Zi}=$ domestic production

$$
\begin{aligned}
& \mathrm{Xi}=\text { vector goods } \\
& \mathrm{Ti}=\text { input vector time }
\end{aligned}
$$

Model household of Ekwueme [7], it is assumed that deposited the smallest child (child care) of the married couple of working mothers:

$$
\text { Utilities: } \begin{aligned}
\mathrm{U} & =\mathrm{f}(\mathrm{C}, \mathrm{L}) \\
\mathrm{U} & =\mathrm{f}(\mathrm{C}, \mathrm{Ld}, \mathrm{Lm}, \mathrm{Lf})
\end{aligned}
$$

Where: $\mathrm{U}=$ utility

$$
\begin{aligned}
& \mathrm{C}=\text { consumption } \\
& \mathrm{Hd}=\text { domestic production hours } \\
& \mathrm{Lm}=\text { hour intermission mother } \\
& \mathrm{Lf}=\mathrm{h} \text { father breaks }
\end{aligned}
$$

A book wich title Everyday Decision Theory and Application of Economics states that every day people make the choice of one of them in time [8]. There is a 24 hour a day, and the individual performing the allocation of time in the day. Allocation of income consumed affects the time to buy goods and services that are needed. The findings of this study explained that the opportunity cost (opportunity cost) of the time spent on an activity that is the value of time to the individual doing the activity alternative left. Budget and time constraints of the budget is a graph to represent this economic principle.

The allocation of time between leisure and working hours are also discussed in the study Görtz [9]. Using the theory of benefit households with activity and time allocation for the husband and wife. Using analysis techniques General Method of Moment (GMM) 3SLS. Finding that the advantages identified households are not associated with domestic production activities, but which households gain extra value from producing activities undertaken by themselves than when done by others e.g. consumption advantages.

\section{MethodOLOGY}

After the text edit has been completed, the paper is ready for the template. Duplicate the template file by using the Save As command, and use the naming convention prescribed by your conference for the name of your paper. In this newly created file, highlight all of the contents and import your prepared text file. You are now ready to style your paper; use the scroll down window on the left of the MS Word Formatting toolbar.

Respondents are working mothers of young children in Palembang with a sample of 234 people. Methods of data collection using interviews, questionnaires and literature. Technical analysis is a binary logistic regression for binary valued dependent variable $(1=$ daycare and $0=$ non daycare $)$. Model analysis are:

$$
\begin{array}{r}
g_{1}(x)=\ln \left[\frac{\pi(x)}{1 \pi(x)}\right]=\beta_{10}+\beta_{11} C+ \\
\beta_{12} \mathrm{Lm}+\beta_{13} \mathrm{Ld}+\beta_{14} \mathrm{Lx}+e_{1}
\end{array}
$$

Where:

$\mathrm{U} \quad=$ utility, the benefits gained working mothers

$\mathrm{C}=$ consumption childcare

$\mathrm{Ld}=$ number of hours of domestic work such as cooking mother, tidy home, caring for her husband and others

$\mathrm{Lm}=$ leisure maternal child care at home, assumed a task for the mother

Lx = leisure hours at home mothers such as bathing, religious activities, reading books, etc.

\begin{tabular}{|c|c|c|c|}
\hline \multirow[b]{2}{*}{ Care Type } & \multicolumn{2}{|c|}{ Custody fees *) } & \multirow[b]{2}{*}{ Total } \\
\hline & $\begin{array}{c}<U S D 1.291 \\
\text { million }\end{array}$ & $\begin{array}{c}>\text { USD 1.291 } \\
\text { million }\end{array}$ & \\
\hline \multirow{2}{*}{ Non Daycare } & 62 & 74 & \multirow{2}{*}{$\begin{array}{l}136 \\
(100) \\
\end{array}$} \\
\hline & $(45.6)$ & $(54.4)$ & \\
\hline \multirow{2}{*}{ Daycare } & 97 & 1 & \multirow{2}{*}{$\begin{array}{l}98 \\
(100)\end{array}$} \\
\hline & $(99.0)$ & $(1,0)$ & \\
\hline \multirow{2}{*}{ Amount } & 159 & 75 & \multirow{2}{*}{$\begin{array}{l}234 \\
(100)\end{array}$} \\
\hline & $(67.9)$ & (32.1) & \\
\hline
\end{tabular}

\section{RESULTS AND DISCUSSION}

With SPSS technical data were processed using binary logistic regression, obtained by calculation as follows:

\section{A. Characteristics of Respondents}

1) Cost of child care: Child care costs are the sacrifices made by the respondent to replace the temporary role of respondents in maintaining and caring for children during the respondents worked. The following table is a resume of the cost of child care:

TABLE I. CHILD CARE COSTS

*) The average cost of care

In Table 1 above to inform you that the cost of the more diversified type of care no daycare greater than the cost of the type of child care daycare. This may imply that the cost of care at daycare fixed amount per month are issued by the respondent. Child care costs have an average cost of US \$ 1.291 million, - while the type of daycare have cost less than the average. This information is gathered from the testimony of the respondent. According to information from the manager daycare, monthly costs incurred standard of Rp 500,000, - for a time deposit from 08.00 till 16.00. If mothers want their children to be given lunch, or add hours of care normally be charged extra. Conversely care costs on the type of non- 
daycare is not fixed amount (flexible) per month so the higher costs to be incurred by the respondent. This is because the cost of the daycare with meeting with details of charges clearly, while it is non daycare is no charge non-economy incurred mother as an expression of gratitude for the assistance of parents and other families in parenting for working mothers such as buying food favorites, buy pulses and so on. Parents or family usually does not ask to be paid for already maintain and care for children of working mothers. This is due to factors affection their blood relationship to the grandson and nephew himself. Grandmother and sisters who care for children are entrusted generally regarded as a solace at a time when their own children are grown and have their own busy life.

2) Domestic hours respondents: Home clock respondents represent the number of respondents in the hours do household chores like cooking. Here's a table that informs many domestic hours respondents:

TABLE II. DOMESTIC HOUR RESPONDENTS

\begin{tabular}{|l|c|c|c|}
\hline \multirow{2}{*}{ Care Type } & \multicolumn{2}{|c|}{ Domestic hour $*$ ) } & \multirow{2}{*}{ Total } \\
\cline { 2 - 3 } & $\mathbf{< 3 . 6 9}$ & $\boldsymbol{> 3 . 6 9}$ & \\
\hline \multirow{2}{*}{ Non Daycare } & 50 & 86 & 136 \\
& $(36.8)$ & $(63.2)$ & $(100)$ \\
\hline \multirow{2}{*}{ Daycare } & 40 & 58 & 98 \\
& $(40.8)$ & $(59.2)$ & $(100)$ \\
\hline \multirow{2}{*}{ Amount } & 90 & 144 & 234 \\
& $(38.5)$ & $(61.5)$ & $(100)$ \\
\cline { 2 - 3 } & \multicolumn{3}{|c|}{ Sources: Primary data is processed, 2017 }
\end{tabular}

*) Average hours of domestic

Table 2 above informs that respondents who chose the type of non-daycare or daycare, have more than the average domestic hour as much as 3.69 hours per day. Based on the interview, this is because the respondent was aware of the responsibilities as mothers and wives, so that when the cooking is still done with an above-average time of 3.69 hours per day with a cooking time of respondents do before leaving for work in the morning and at night,

3) Other leisure hours: Other leisure hours of the respondents is the amount of time respondents in conducting individual leisure time such as hobbies, conduct religious activities and so forth. The following table tells you how many hours of rest the respondents:

TABLE III. OTHER LEISURE HOURS

\begin{tabular}{|l|c|c|c|}
\hline \multirow{2}{*}{ Care Type } & \multicolumn{2}{|c|}{ Other Leisure Hours *) } & \multirow{2}{*}{ Total } \\
\cline { 2 - 3 } & $\mathbf{< 3 . 9 2}$ & $\mathbf{3 . 9 2}$ & \\
\hline \multirow{2}{*}{ Non Daycare } & 40 & 96 & 136 \\
& $(29.4)$ & $(70.6)$ & $(100)$ \\
\hline \multirow{2}{*}{ Daycare } & 35 & 63 & 98 \\
& $(35.7)$ & $(64.7)$ & $(100)$ \\
\hline \multirow{2}{*}{ Amount } & 75 & 159 & 234 \\
\cline { 2 - 3 } & $(32.1)$ & $(67.9)$ & $(100)$ \\
\hline
\end{tabular}

Sources: Primary data is processed, 2017

*) Average hours more leisure

Table 3 above to inform you that the respondent had more leisure time an average of 3.92 hours per day. Respondents either entrust in non-daycare and leave in a non-daycare have more leisure hours than average. This means that with the help of child care the respondent had the assistance of child care so that the time allocated to other breaks can be used flexibly by the respondent.

4) Hours parenting: Hours caring for children is the amount of time that can be used by respondents in child care at home after the respondent returned home from work. Here's a table that informs the number of hours respondents in parenting:

TABLE IV. HOURS PARENTING RESPONDENTS

\begin{tabular}{|l|c|c|c|}
\hline \multirow{2}{*}{ Care Type } & \multicolumn{2}{|c|}{ Leisure Hours Parenting *) } & \multirow{2}{*}{ Total } \\
\cline { 2 - 3 } & $<8.83$ & $>8.83$ & \\
\hline \multirow{2}{*}{ Non Daycare } & 62 & 74 & 136 \\
& $(45.6)$ & $(54.4)$ & $(100)$ \\
\hline \multirow{2}{*}{ Daycare } & 51 & 47 & 98 \\
& $(52.0)$ & $(48.0)$ & $(100)$ \\
\hline \multirow{2}{*}{ Amount } & 113 & 121 & 234 \\
\cline { 2 - 3 } & $(48.3)$ & $(51.7)$ & $(100)$ \\
\hline \multicolumn{2}{|c|}{ Sources: Primary data is processed, 2017 }
\end{tabular}

*) Average hours of parenting

Table 4 above to inform you that the majority of respondents have a number of hours of child care at home above the average 8.83 hours per day. This is because the respondents already have his help to do other work at home so that the allocation of parenting time can be performed entirely by the respondent after working outside the home. Also means that the responsibility and awareness of the obligations of the respondents as a working mom has been very good.

\section{B. Primary Data Sports Results}

\section{Goodness of Fit}

Simultaneous

\begin{tabular}{lclc}
\hline $\begin{array}{l}\text { Hosmer and } \\
\text { Lemeshow Test }\end{array}$ & $\begin{array}{c}\text { Nagelkerke } \mathrm{R} \\
\text { Square }\end{array}$ & Classification Table \\
\hline Sig 320 320 & .660 & $\begin{array}{l}\text { Percentage } \\
\text { Correct }\end{array}$ & 859 \\
& & \\
\hline Sources: Primary data is processed, 2017
\end{tabular}

Fig. 1. Results of testing goodness of fit and simultaneous.

In figure 1 is obtained Nagelkerke $\mathrm{R}$ Square of 0.660 . These results suggested that the proportion of variance explained by the $\mathrm{U}$ is capable of $\mathrm{RC}, \mathrm{Ld}, \mathrm{Lx}$, and $\mathrm{Lm}$, was $66.0 \%$.

From SPSS output (Variables in the Equation), obtained by Statistics Test Wald (Wald) and P-value (Sig.) For each predictor variable as follows:

- Regression constants obtained was 16.831 (a positive value) which gives the sense that any influence of predictor variables affect the chances of success are utilities Daycare nursery.

- The regression coefficient on the variable RC obtained by -4.985 the statistical value of the Wald test 39.940and a $\mathrm{P}$-value of 0.000 . These results indicate 
that the value of the $\mathrm{P}$-value $<\alpha$ with $\alpha=5 \%$, in order to obtain a decision which rejected $\mathrm{H} 0$ lead to the conclusion that there is a significant and negative effect of $\mathrm{RC}$ on $\mathrm{U}$. This means that the larger RC (cost of childcare) paid the mother, the more there is little likelihood of success utilities daycare child care; and vice versa the smaller RC (cost of childcare) paid the mother, the greater the likelihood of success there are utilities Daycare nursery. Based on the output odds ratio (Exp (B)), obtained odds ratio for RC for0.007 where it is interpreted that the $\mathrm{RC}$ of the utility Non Daycare Child care is $1 / 0.007=142.857$ time of RC Daycare. In other words, RC (cost of childcare) Non Daycare nursery utility greater than the Daycare.

- The regression coefficient on the variable Ld obtained by -1.316 the statistical value of the Wald test 20.080and a P-value of 0.000 . These results indicate that the value of the $\mathrm{P}$-value $<\alpha$ with $\alpha=5 \%$, in order to obtain a decision which rejected $\mathrm{HO}$ lead to the conclusion that there is a significant and negative effect $\mathrm{Ld}$ against $\mathrm{U}$. This means that the greater $\mathrm{Ld}$ (the number of hours of domestic work) owned by mother, the less likely there is a successful daycare utility; and vice versa the smaller Ld (the number of hours of domestic work) owned by the mother, the greater the likelihood of success there are utilities Daycare nursery. Based on the output odds ratio (Exp (B)), odds ratios for Ld obtained by 0.268 , This means that the Ld of the utility Non Daycare Child care is $1 / 0.268=3.73$ time of Ld Daycare. In other words, Ld (the number of hours of domestic work) utility Non Daycare Child care is greater than the Daycare.

- The regression coefficient on the variable Lx obtained for -0.379 the statistical value of the Wald test 3.065and a P-value of 0.080 . These results indicate that the value of the P-value $>\alpha$ with $\alpha=5 \%$, in order to obtain a decision which resulted in the conclusion $\mathrm{H} 0$ is accepted that there are not significant and negative effect $\mathrm{Lx}$ against $\mathrm{U}$. This means that the greater the Lx (the number of leisure hours more) owned the mother, the less likely there is a successful daycare utility; and vice versa the smaller Lx (the number of leisure hours more) owned by the mother, the greater the likelihood of success there are utilities Daycare nursery. Based on the output odds ratio $(\operatorname{Exp}(\mathrm{B}))$, odds ratios obtained for Lx by0.685, This means that the utility Lx of Non Daycare Child care is 1/0.685Daycare $\mathrm{Lx}=1,460$ time. In other words, Lx (the number of leisure hours more) Non Daycare nursery utility greater than the Daycare.

The regression coefficient on the variable Lm obtained for 0.795 the statistical value of the Wald test 22.235and a P-value of 0.000 . These results indicate that the value of the $\mathrm{P}$-value $<\alpha$ with $\alpha=5 \%$, in order to obtain a decision which rejected $\mathrm{H} 0$ lead to the conclusion that there is significant influence $\mathrm{Lm}$ to the U. It is understood that the greater the Lm (number of hours caring) owned by the mother, the less the likelihood of success there are utilities daycare child care; and vice versa the smaller Lm (number of hours caring) owned by the mother, the greater the likelihood of success there are utilities Daycare nursery.
Based on the output odds ratio (Exp (B)), obtained odds ratio amounted to Lm.451, This means that the utility Lm of Non Daycare Child care is $1 / .451=2,217$ time of Lm Daycare. In other words, Lx (the number of leisure hours more) Non Daycare nursery utility greater than the Daycare.

Logistic Regression Model with equations involving all the variables have the following results:

$$
\begin{gathered}
\ln \left(\frac{\pi(x)}{1-\pi(x)_{i}}\right)=16,831-4,985 R C-1,316 L d- \\
0,379 L x-0,795 L m \\
\pi(x)=\frac{e^{16,831-4,985 R C-1,316 L d-0,379 L x-0,795 L m}}{1+e^{16,831-4,985 R C-1,316 L d-0,379 L x-0,795 L m}}
\end{gathered}
$$

Where :

$\mathrm{U}=$ Utility or the benefits obtained by the mother works at daycare or Non Daycare

$\pi(\mathrm{x})=$ Probability of success there Daycare Child care utility.

\section{Analysis of Consumption and Time Allocation Working Mom}

Statistical calculation results obtained from independent variables significantly and negatively affect ie child care costs (RC), the number of domestic clock (Ld), the number of child care hours $(\mathrm{Lm})$ while the number of leisure hours more $(\mathrm{Lx})$ affects not significant. This means that the respondent (mother worked) possibility of choosing the type of daycare lower storage when affected child care costs (RC), the number of hours of domestic work (Ld), the number of hours of child care at home (Lm) higher.

1) Cost of child care influence on demand child care: Child care costs (RC) as described above are concerned the mother works. The statistic shows that the higher the cost of child care daycare types possibility of working mothers (respondent) did request the type of daycare lower. In the sense that the respondent (a working mother) would prefer a day care type of daycare with a record when daycare costs less than the cost of the type of non daycare. It can be a suggestion for the management costing daycare that is not too high. In the primary data is known that the standard fee per child daycare ranges from $\mathrm{Rp} 500,000$, - in the city of Palembang. The cost information is obtained from the management of storage-type daycare. When coupled hour concierge and add other facilities such as lunch, the cost will be increased at the request of parents children are entrusted. Determination of these child care costs of the interview is not too burdensome for the elderly, because the cost of child care for the respondents is the substitution effect of working mothers. By working mother has an income, some of which are allocated for child care costs. This is called the substitution effect is when there are changes in prices (cost of childcare) to change the number of working hours of women offered. Where the existence of a paid child care (daycare) greatly assist the mother in choosing 
childcare and for some of the respondents may be the last alternative option if no parents, family, father or caregiver to assist mothers during the mother works outside the home. This is in accordance with the opinion of Duncan, Simon et al. look at the policies and values in the household in the United Kingdom (UK) where both parents work and make costbenefit calculations (cost-benefit) in choosing childcare [10]. Further discussed choosing childcare is part of the modernization of the domestic economy (modernized household economics) where trade-offs between costs and revenues of working mothers.

2) Time allocation influence on demand daycare: Number of hours of domestic work (Ld) and the number of hours of child care at home $(\mathrm{Lm})$ of the respondents and negatively affect significantly the likelihood of respondents choosing child care daycare. This means that statistically that the higher the number of hours of domestic work (Ld) and the number of hours of child care at home $(\mathrm{Lm})$ of the respondents the lower the possibility of working mothers utility and ask daycare type of daycare. The calculations show that the utility of working mothers and ask daycare more likely to choose the type of non daycare nursery. These results show that respondents in this study has a number of domestic and number of clock hours of child care at home is greater than the possibility of working moms feel the utility on election day care daycare type of care. This is due to the energy assistance at home for the mother after a day of work in the public, so that mothers feel more comfortable with the type of non daycare. The result of this calculation is also in accordance with the respondent descriptive statistics in Table 2 that the majority of respondents have a domestic clock above the average of 3.89 hours per day, and Table 4 that the majority of the respondents have children at home caring hour average below 8.83 hours per day, Of the two leisure time allocation, more mothers giving more time to care for children under six years after being in the house, let alone have the assistance of others in the house can be diverted only to give attention to the child. Form of allocation of mothers such as these show that the mother as the respondent had the attention and responsibility to the various activities in the domestic sector, which is in line with the theory of Elfindri that there is a joint production between the activities of home and leisure mean the unit the same time often used for home and leisure activities simultaneously [3]. And in contrast to the findings of Kimmel and Connelly that working mothers have the allocation of time to watch domestic and hours of leisure more less on weekdays (weekdays) and have hours of domestic as many hours of child care at home and working hours on the weekend (weekend) [11]. While the results of the study found that every day of the respondents as a working mother can allocate an average time of over 3 hours per day either on domestic hours, more leisure hours and hours of child care. This proves that the respondents as working mothers remain aware of its responsibilities as a wife and a good mother even had a job in the public sector.
Respondents still comfortable leaving a child in the grandparents, relatives, neighbors and even your husband / partner during the work. From the interviews several respondents that they are more trusting his own father and mother or father and mother-in-law due to proven experienced and successful care for, nurture, educate their children to adulthood, marriage, work and have children. So feel comfortable leaving children with their parents or in-laws themselves than others. This result contradicts from a survey conducted by Duncan, Simon et al. examined the assumption of working mothers and couples who also work in selecting child care in the UK [10]. Respondents from the middle (middle class) many choose daycare / nursery care with daycare good reason for the development of the social level and the level of learning for children. Election of childcare is a process of moral and emotional combination in meeting the needs of children and even their own mother needs a balance between the needs of children and mothers. Kids can meet a lot of people are different teachers and friends with the characteristics of each so as to help children to socialize with other people not only met with the mother alone during the day, and to foster the development of good emotions such as sharing food, sharing toys and etc. The level of development of learning is also excellent as language, communication, song, music, coloring and others, so that in the UK leave their children in daycare has become a necessity for parents both working mothers and mothers do not work because of daycare is not just a child care course but also as a school of early childhood learning methods are clearly given by professionals in the field of early childhood education. While in Indonesia, daycare industry is not well developed.

\section{CONCLUSIONS}

The conclusion of this study are:

- The effect of the cost of the utility of working mothers are significant and negative means the greater the RC (cost of childcare) paid the mother, the less likely there is a successful daycare utilities; and vice versa the smaller RC (cost of childcare) paid the mother, the greater the likelihood of success there are utilities Daycare. Means that the RC (cost of childcare) Non Daycare nursery utility greater than the Daycare. The results of this study differ from the findings of Duncan, Simon et al. which states that working mothers and couples who also work in the UK prefer to leave their children in daycare to daycare good reason for the development of the social level and the level of learning for children [10]. Election of childcare is a process of moral and emotional combination in meeting the needs of children and even their own mother needs a balance between the needs of children and mothers.

- The number of hours of domestic work (Ld) and the number of hours of child care at home (Lm) of the respondents and negatively affect significantly the likelihood of respondents choosing child care daycare. This means that statistically that the higher the number of hours of domestic work (Ld) and the number of hours of child care at home ( $\mathrm{Lm})$ of the respondents the lower the possibility of working mothers utility and ask 
daycare type of daycare. Means that the allocation of time (Ld and Lm) Non Daycare nursery utility greater than the Daycare. While the number of hours of other working mothers do not affect significantly the possibility of working mothers utility choosing child care. But simultaneously the respondent can allocate time above the average of 3.89 hours per day for utilities possibility of working mothers. The results of this study different from the findings of Kimmel and Connelly that working mothers have the allocation of time to watch domestic and hours of leisure more less on weekdays (weekdays) and have hours of domestic as many hours of child care at home and working hours on weekends (weekend) [11].

\section{ACKNOWLEDGMENT}

This paper is one part of a doctoral dissertation research in which the author is a graduate from Economic Sciences Doctoral Study Program University of Sriwijaya. The author would like to thank promoter team and the test team over the criticism and constructive feedback is also thanks to the strengthening of the Directorate General of Research and Development Kemenristekdikti which has provided funding through research grants doctoral dissertation in 2017.

\section{REFERENCES}

[1] M. Lupikawaty, "Comparison of Female Labor Force Participation Labor Women Indonesia and Thailand". Orasi Bisnis ISSN: 2085-1375 Issue IX,2013

[2] BPS, Employment Situation South Sumatra Province in August 2014. Press Release No. 64/11/16 / Th.XVI, November 5, 2014

[3] E. Elfindri and N. Bachtiar, Labor economics. Andalas Padang: Publisher University Press, 2004.

[4] BPS, Sumsel In Figures per City. South Sumatera Province: Catalog BPS, 2016

[5] UNESCO, Paris. "Policy Review Report: Education and Early Childhood Care in Indonesia. Section ECD and Inclusive Education Division of Basic Education". 2005

[6] G.S. Becker, "A Theory of the Allocation of Time". The Economic Journal, vol. 75, pp.493-517, 1965.

[7] D.U. Ekwueme, An economic Analysis of Child Care and The Household's Decision Work. Dissertation. Wayne State University Detroit Michigan, 1996

[8] A. Schmitz, "Everyday Decision. Theory and Application of Economics. v.1.0. Chapter 4 : Individual and Households", 2012 [Online] Retrieved from: https://2012books.lardbucket.org/pdfs/theory-and-applications-ofeconomics.pdf.

[9] M. Görtz, "Leisure, Household Production, Consumption and Economic Well-being". Thesis Ph.D. Department of Eonomics University of Copenhagen, 2006.

[10] S. Duncan, Mothers and Child Care: Policies, Values and Theories. Children \& Society (in press). Published online in Wiley InterScience, 2003.

[11] Kimmel and Connelly. "Is Mothers' Time With Their Children Home Production or Leisure?" IZA Discussion Paper No. 2058, 2006. 